\title{
Degrees of captivity and aggressive behavior in domestic Norway rats
}

\author{
ROBERT BOICE and NELSON ADAMS \\ State University of New York, Albany, New York 12222
}

\begin{abstract}
Six categories of aggressive behaviors were studied in groups of domestic rats observed for 3 months and in three settings of varying degrees of captivity. In the least captive situation, a large outdoor pen, aggression frequently took a wild-type form (aggressive side postures, biting attacks) and infrequently took a "playful" form (pins, aggressive grooms) relative to aggression shown by rats in the most captive situation, laboratory cages. Rats housed in an intermediate degree of captivity showed intermediate levels of both serious and playful types of aggression. Male and female intruders were attacked by residents of all three settings, most seriously in the outdoor pen. These results indicate that captivity may have a powerful effect on the form of aggression shown by domestic rats.
\end{abstract}

Despite the prolonged accumulation of information on captive Norway rats, we still know very little about the effects of captivity on their behavior (Boice, 1981b). The indication is that captivity may be an enormously powerful variable.

One advantage of studying captivity is that specification of its parameters may help cledr up confusion about other behavioral processes like domestication. Traditionalists have dictated a view of domestication as being behaviorally degenerative (Boice, 1973). But recent research has shown that wild-type patterns related to courtship (Miller, 1977), to burrowing (N. Adams \& Boice, 1981; Boice, 1977; Flannelly \& Lore, 1977), and to emotional reactivity (Boice, 1981b; Clark \& Galef, 1977) appeared when domestic animals were placed in situations with naturalistic "releasers." Despite those observations, no clear specification of the effects of captivity on aggression has heretofore been published.

The evident result of neglecting captivity is persistent controversy about whether or not domestic Norway rats show the complete repertoire of wild-type aggressive behaviors (Barnett \& Hocking, 1981; Lore \& Flannelly, 1981). Thus, although accounts of wild-type aggression in domestic rats appear in the literature (Blanchard, Takahashi, \& Blanchard, 1977; Boice, 1972; Nikoletseas \& Lore, 1981), traditionalists persist in claiming that 'the 'agonistic' behavior of domestic rats is usually much attenuated in comparison with that of the wild type" (Barnett, Dickson, \& Hocking, 1979, p. 105).

One apparent reason that this debate continues is the disagreement about what conditions of captivity are relevant to a proper test. Lore and Flannelly (1981), on one hand, maintain that Barnett (1958) errs in not raising his domestic rats in situations with naturalistic shelter during early development. Barnett and Hocking (1981), on the other hand, view their procedure as sufficient to conclude that their domestic colonies (unlike laboratory groupings of wild rats) were "peace- ful." Another source of confusion is that claims of attenuated aggression in domestic rats are often based upon observations of within-group social interactions. Suggestions that domestic rats show the full aggressive behavioral repertoire have been based upon studies of interactions between colony residents and intruders (e.g., Blanchard et al., 1977). What remains, then, is the need for a more systematic examination of the effects of environmental conditions on the aggressive behaviors of domestic rats, both within groups and against intruders. The present study examines captivity at three different levels (laboratory cages with nest boxes, laboratory pen with burrows, large outdoor enclosure) in relation to six categories of aggressive behaviors in groups of domestic rats.

\section{METHOD}

\section{Subjects}

Sprague-Dawley albino rats, aged 70-220 days, purchased from a commerical supplier (Taconic Farms) were employed throughout this study. A mixed-sex group of 7-10 adult rats composed the outdoor group; the variation in group size reflects the attrition rate that may occur in a newly established outdoor group prey to owls, hawks, and inclement weather. A mixedsex group of seven rats was housed in the indoor pen. And samesex groups of three rats were housed in eight laboratory cages. We chose not to employ mixed-sex groups in this most captive condition, in part because the production of litters would have led to confounds including overcrowding and in part because this arrangement more closely approximates the typical housing procedure of laboratory studies.

\section{Enclosures}

The outdoor enclosure is described elsewhere (Boice \& Adams, 1980). Briefly, it is constructed of wire-mesh walls over a wooden frame $6 \times 12 \times 2 \mathrm{~m}$ in dimension, plus $.6 \mathrm{~m}$ of fencing below ground level. Two strands of electrically charged wire are positioned near the base of the walls to discourage rats from climbing on the fencing. The dirt substrate of this enclosure is a mixture of soils designed to encourage burrowing by inhabitants. Water was continuously available from a poultry watering can.

The indoor pen is a $1.5 \times 2 \times 1 \mathrm{~m}$ structure of glass walls supported by a wooden frame. It contains a $.5-\mathrm{m}$ layer of soil 
like that in the outdoor enclosure. Water was continuously available from an identical watering can.

The laboratory cages with attached nest boxes are described in Boice (1971b). Briefly, they are constructed of expanded metal sides and glass fronts and tops, in all, $30 \times 60 \times 30 \mathrm{~cm}$. Two nest boxes were attached to each cage.

\section{Procedure}

Recording aggressive behaviors of residents. Observations of rats in the outdoor enclosure were made for $90 \mathrm{~min}$ on each day of the week at dusk over 3 months. Laboratory chow was made available at this time to encourage the emergence of rats from their burrows. Two observers collected data during 2-min time samples of activity at 15 -min intervals; social behavior was recorded ad lib (Altmann, 1974). Observations of the indoor pen colony were comparable; that is, observations were made during the first $90 \mathrm{~min}$ of the dark cycle. Caged groups were observed in similar fashion, but for 60 -min periods during the first $1 \mathrm{~h}$ of the dark cycle. Because demands on observers were increased in the cage situation by the relatively higher rates of social behavior, the total duration of recording was shortened and all data were collected in a series of 2-min time samples from one cage at a time.

Aggressive behaviors as described by D. B. Adams (1976), Barnett (1958), and Grant and Mackintosh (1963) were selected for study here: (1) pinning, (2) aggressive grooming, (3) boxing, (4) chasing, (5) aggressive side posture, and (6) biting attack.

Intruders. Male and female rats, also of Sprague-Dawley stock, were individually tested in all three housing contexts as intruders, 16 ( 8 males) each. Intruder rats had been reared from weaning in laboratory cages in same sex groups of three. They were systematically observed as were the caged rats described above: for 3 weeks, between the ages of 70-90 days, for measurements of "spontaneous" dominance, and followed by 1 week of water competition tests (Baenninger, 1970). Baenninger's procedures were used to judge one animal from each threesome as "dominant" and one as "submissive"; these two rats then served as intruders, the former group labeled "high status" and the latter in a group labeled "low status." Intruders were placed into one of three housing situations at approximately 4-day intervals during the latter half of the 3-month period of observations. Each intruder remained with the resident group for a 24-h period. In the instance of caged residents (who were not mixed-sex groups), intruders of the opposite sex and of different status were not used. In addition to recordings of the aforementioned six categories of aggressive behavior exhibited by residents toward intruders, observers noted the wounds and weight losses incurred by intruders.

\section{RESULTS}

\section{Aggressive Behaviors Within Groups}

The profile of aggressive behaviors among colony members varied dramatically across the three environments, with more playful or harmless types of aggression prevailing in the laboratory setting, and more serious (i.e., wild-type) forms standing out as the degree of captivity was lessened. This pattern of the effect of captivity may be seen in Figures 1-3. Figure 1 depicts the relative occurrence of pins (i.e., the resolution of wrestling) and aggressive grooms in the three housing situations. With these relatively nonserious forms of aggression, rates were far higher in the indoor, more captive contexts. Figure 2 illustrates the frequency configuration of boxing and chasing behavior. Boxing was more frequent in both indoor settings, but much less so than pins and aggressive grooms (Figure 1).

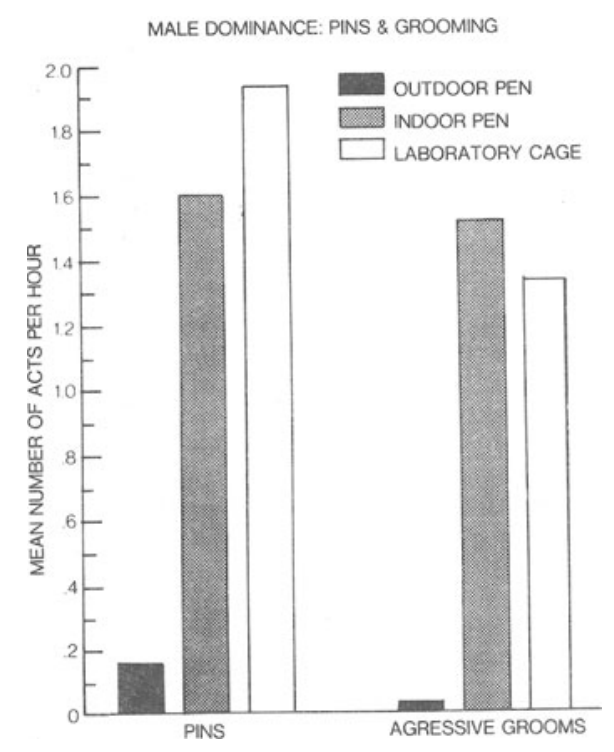

Figure 1. Relative frequency of "playful" aggressive behaviors across the three levels of captivity.

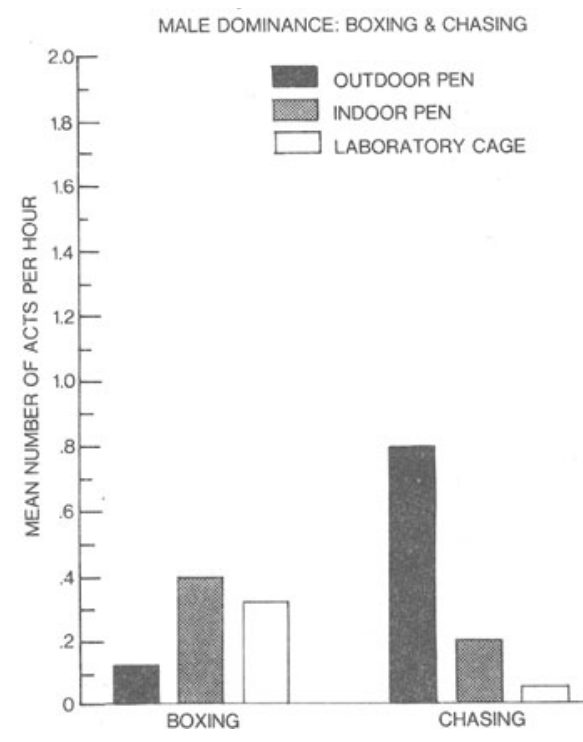

Figure 2. Relative frequencies of boxing and chasing behaviors across the three environments.

Chasing, a serious form of aggression, was several times more common in the outdoor enclosure than in either indoor setting. Consistent with that trend, Figure 3 shows that the two "wild-type" forms of aggression, aggressive side postures and biting attacks, were clearly most common in the outdoor enclosure, were intermediately common in the laboratory pen, and were least common in the laboratory cages.

Female residents of the same three housing situations showed the same basic pattern of responding, but at much lower and somewhat unreliable rates. 
Aggression of Residents Toward Intruders

Toward male intruders. Figure 4 depicts the pattern of aggressive responses (threats, biting attacks, and wounding) directed at male interlopers. Aggression in the form of biting attacks was more common, and more severe as judged by wounding, in the outdoor enclosure than in the laboratory cages. Although they directed more biting attacks toward male intruders than did their counterparts in cages, residents of the indoor pen did not afflict a greater number of wounds on male intruders.

Figure 4 also shows an effect of the prejudged social status of an intruder on the aggression delivered by

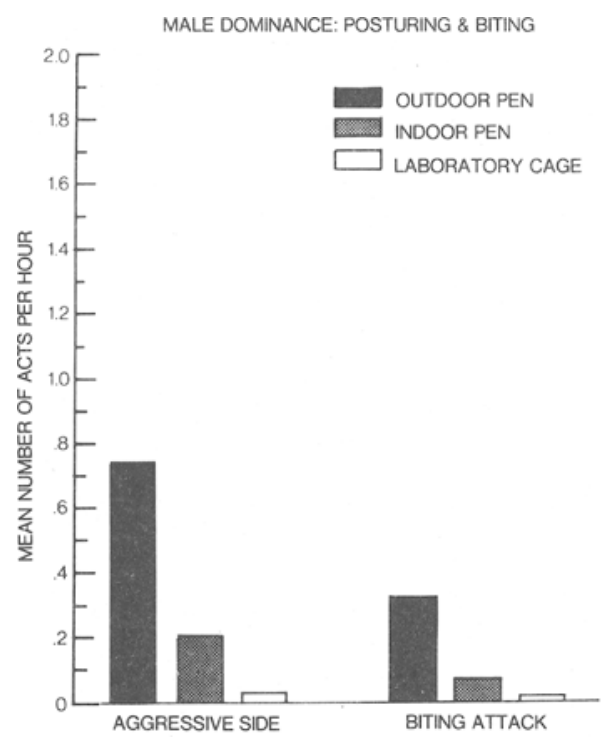

Figure 3. Relative frequency of serious aggressive behaviors across the three degrees of captivity.

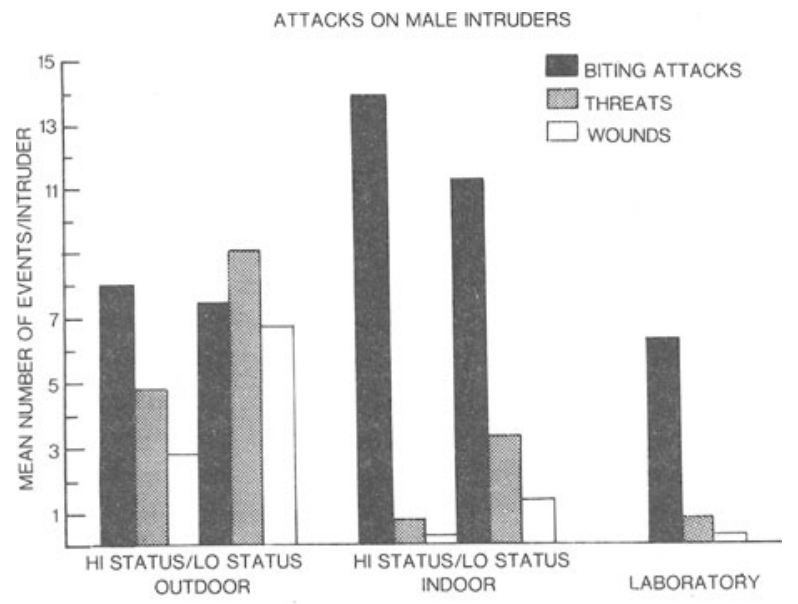

Figure 4. Number of threats (pins, aggressive grooms, and aggressive side posturing), biting attacks, and wounds incurred by male intruders from the residents of the three captive environments.

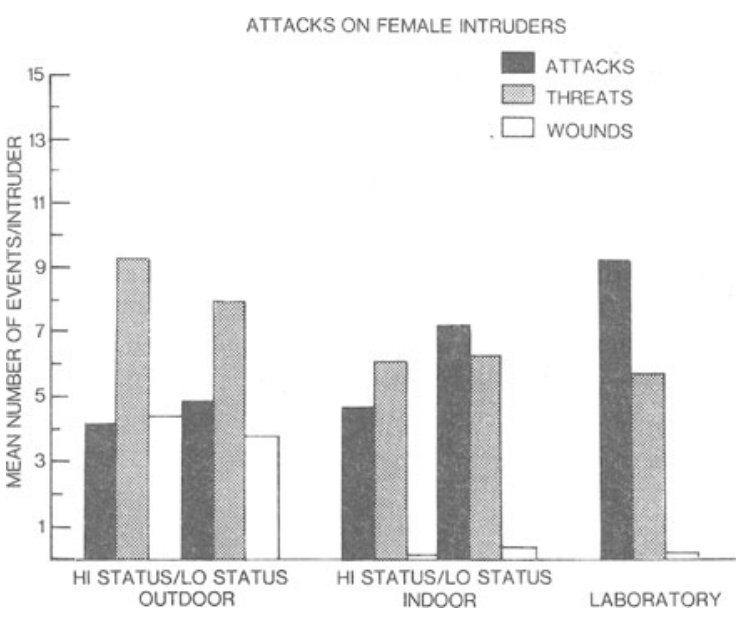

Figure 5. Number of threats, biting attacks, and wounds incurred by female intruders from (female) residents across the three levels of captivity.

residents. Low-status male intruders were attacked more often and received more wounds than high-status male intruders did. These differences were reliable despite the variability resulting from differences in responding across situations.

Toward female intruders. Female intruders were attacked more often than were male intruders, and nearly as often in the indoor settings as outdoors. Nonetheless, the severity of attacks was noticeably greater, and wounding was far more likely in the outdoor enclosure (Figure 5). In contrast to the case of male intruders, the prejudged social status of female intruders had no obvious effect on the behavior of the residents. Another interesting difference for female intruders was the lower rate at which they elicited threats from female residents. This result apparently was due to the fact that female intruders were typically attacked by female residents, who displayed little preliminary posturing.

\section{DISCUSSION}

Captivity seemed to have a clear effect on the form of aggressive behaviors shown by domestic Norway rats. Wild-type behaviors (within groups) such as chasing, side posturing, and biting were almost exclusively limited to the two relatively noncaptive situations: the indoor pen and the large outdoor pen. It may not be surprising, then, that other researchers would report an absence of wild-type behaviors of domestic groups housed analogously to the laboratory groups of rats in this study. Given the clear demonstration that wild-type aggression does occur within groups in more naturalistic settings, there may be less justification in claims that the "complete repertoire of attack and defense of Rattus norvegicus" can "be studied only among rats of the wild type" (Barnett \& Hocking, 1981, p. 263). Accordingly, it appears that Lore and Flannelly (1981) were correct in concluding that "developmental factors including age, previous social experience, and physical aspects of the rearing environment play a surprisingly important role in the expression of aggression in this species" (p. 153). 
Several other important implications may be drawn from the results of this study. First, domestication does not appear to have deprived laboratory rats of the potential for basic and functional behavioral patterns, including aggression. This point bears restating because of continuing claims that domestic rats are less than adequate for behavioral study (cf. Boice, 1973, 1981b). Second, while we do claim that domestic rats are readily able to display the full range of wild-type aggressive behaviors, we do not suppose that genotype is irrelevant (Price, 1978; Price \& King, 1968). Clearly, wild rats are genetically different; their social behavior in crowded laboratory cages is typically more intense than that of domestic rats (Boice, 1972). But the fact that wild rats behave differently in captivity may also be partly due to effects of captivity, including sampling artifacts (Boice, 1971a), early experience with emotional mothers (Hughes, Harlan, \& Plaut, 1977; Price \& Belanger, 1977), rearing in burrows (Boice, 1981b), and life in outdoor environments. Proper conclusions about what wild or domestic rats can do should be based on an appreciation of their behavior across the degrees of captivity.

The third point is that the manipulation of captivity used here, while admittedly preliminary, produced an orderly continuum of meaningful results. Thus, serious-type aggressive behaviors became more common and "playful" types became less common as the degree of captivity was decreased from laboratory cages to an indoor pen with burrows to a large outdoor enclosure. Similarly, attacks on intruders increased in severity as the degree of captivity lessened.

Finally, the present results help extend another important and overlooked point about captivity (Boice, 1981b): Its effects may be seen in both negative and positive perspectives. The temptation might be to regret the greater incidence of more playful types of aggression shown by domestic rats grouped in laboratory cages. But, as a rule, this apparent effect of captivity is consistent with the needs of laboratory researchers for subjects who are not fighting intensely. Consider, too, that the greater playfulness of captive domestic rats may be consistent with the demands of psychological research in which behavioral flexibility and learning are at a premium (Boice, 1981a). Thus, if we are to formulate generalizable notions about the behaviors of Norway rats, we must, as observers, be willing to study them in a systematic array of contexts (Boice, 1983). Having done that, we may be able to conclude that noncaptive situations are most appropriate for the investigation of attack and defense, and that captive contexts are most conducive to the appearance of more harmless forms of aggression in domestic Norway rats.

\section{REFERENCES}

AdAms, D. B. The relation of scent-marking, olfactory investigation, and specific postures in the isolation-induced fighting of rats. Behaviour, 1976, 56, 286-297.

Adams, N., \& Boice, R. Mouse (Mus) burrows: Effects of age, strain, and domestication. Animal Learning \& Behavior, 1981, 9, 140-144.

Altmann, J. Observational study of behaviour: Sampling methods. Behaviour, 1974, 48, 1-41.

Baenninger, L. P. Social dominance orders in the rat: Spontaneous, food, and water competition. Journal of Comparative and Physiological Psychology, 1970, 71, 202-209.

BARNetT, S. A. An analysis of social behaviour in wild rats.
Proceedings of the Zoological Society of London, 1958, 130, 107-152.

Barnett, S. A., Dickson, R. G., \& Hocking, W. E. Genotype and environment in the social interactions of wild and domestic "Norway" rats. Aggressive Behavior, 1979, 5, 105-119.

Barnetr, S. A., \& Hocking, W. E. Further experiments on the social interactions of domestic "Norway" rats. Aggressive Behavior, 1981, 7, 259-263.

Blanchard, R. J., Takahashi, L. K., \& Blanchard, D. C. The development of intruder attack in colonies of domestic rats. Animal Learning \& Behavior, 1977, 5, 365-369.

BoIce, R. Excessive water intake in captive Norway rats with scarmarkings. Physiology \& Behavior, 1971, 7, 723-725. (a)

BoICE, R. Laboratizing the wild rat (Rattus norvegicus). Behavior Research Methods \& Instrumentation, 1971, 3, 177-182. (b)

Boice, R. Some behavioral tests of domestication in Norway rats. Behaviour, 1972, 42, 198-231.

Boice, R. Domestication. Psychological Bulletin, 1973, 80, 215 230.

Boice, R. Burrows of wild and albino rats: Effects of domestication, outdoor raising, age, experience, and maternal state. Journal of Comparative and Physiological Psychology, 1977, 91, 649-661.

BoICE, R. Behavioral comparability of wild and domestic rats. Behavior Genetics, 1981, 11, 545-553. (a)

Borce, R. Captivity and feralization. Psychological Bulletin, 1981, 89, 407-421. (b)

BoIce, R. Observational skills. Psychological Bulletin, 1983, 93, 3-29.

Boice, R., \& Adams, N. Outdoor enclosures for feralizing rats and mice. Behavior Research Methods \& Instrumentation, 1980, 12, 577-582.

Clark, M. M., \& Galef, B. G. The role of physical rearing environment in the domestication of the gerbil (Meriones unguiculates). Animal Behavior, 1977, 25, 298-316.

Flannelly, K., \& Lore, R. Observations of the subterranean activity of domesticated and wild rats (Rattus norvegicus): A descriptive study. Psychological Record, 1977, 27, 315-329.

Grant, E. C., \& Mackintosh, J. H. A comparison of the social postures of some common laboratory rodents. Behaviour, 1963, 21, 246-259.

Hughes, C. W., Harlan, R. S., \& Plaut, S. M. Maternal behavior of wild and domestic Rattus norvegicus recorded continuously in dual-chambered cages. Developmental Psychobiology, 1977, 11, 329-334.

Lore, R. K., \& Flannelly, K. J. Comparative studies of wild and domestic rats. Aggressive Behavior, 1981, 7, 253-257.

Miller, D. B. Social displays of mallard ducks (Anas plabyrhynchos): Effects of domestication. Journal of Comparative and Physiological Psychology, 1977, 91, 221-232.

Nikoletse As, M., \& LoRe, R. K. Aggression in domesticated rats reared in a burrow-digging environment. Aggressive Behavior, 1981, 7, 245-252.

Price, E. O. Genotype versus experience effects on aggression in wild and domestic Norway rats. Behaviour, 1978, 64, 340-353.

Price, E. O., \& Belanger, P. L. Maternal behavior of wild and domestic stocks of Norway rats. Behavioral Biology, 1977, 20, 60-69.

Price, E. O., \& King, J. A. Domestication and adaptation. In E. S. E. Hafez (Ed.), Adaptation of domestic animals. Philadelphia: Lea \& Febiger, 1968. 